\title{
Variación somaclonal y selección in vitro con toxinas como herramienta en la búsqueda de resistencia a enfermedades en plantas: Revisión
}

\author{
Carlos Patiño Torres \\ cpatinot@yahoo.com \\ Escuela de Ciencias Agrícolas, Pecuarias y del Medio Ambiente. \\ Universidad Nacional Abierta y a Distancia CEAD Palmira, Colombia
}

\begin{abstract}
Resumen.- La diversidad alélica es un requisito fundamental para el éxito de los programas de fitomejoramiento. En casos en los que la reserva de genes es escasa existen varios mecanismos para aumentarla artificialmente, incluyendo la obtención de variantes somaclonales a través de técnicas de cultivo de tejidos vegetales in vitro. La variación somaclonal es un fenómeno natural que ocurre en los procedimientos de cultivo de tejidos, a través del cual pueden recuperarse mutantes con o sin ventajas adaptativas. Cuando este fenómeno se utiliza para generar mutantes con características prediseñadas, a través del uso de un agente de selección artificial, el proceso se denomina selección in vitro. Si lo que se busca es producir material vegetal con resistencia y/o tolerancia a enfermedades, el agente de selección puede ser el microorganismo etiológico, sus partes, o sus productos metabólicos, incluidas sus toxinas. Consideraciones de costo, sencillez y eficacia, hacen que esta técnica sea particularmente apta para los países en vía de desarrollo. En este documento se revisan los fundamentos científicos que la sustentan.
\end{abstract}

Palabras clave: Cultivo de tejidos, Resistencia a enfermedades, Selección in vitro, Variación somaclonal.

Allelic diversity is a fundamental requirement for successful plant breeding programs. When gene pool is limited, several mechanisms are available for variability enrichment, for example, obtaining somaclonal variants through in vitro techniques. Somaclonal variation is a natural phenomenon that occurs in the procedures of plant tissue culture, through is possible to recover mutants with or without adaptive advantages. When this phenomenon is used to generate mutants with specific traits, through the use of an agent of artificial selection, the process is called in vitro selection. When looking for generating plant material that is resistant/tolerant to diseases, the agent of choice may be the causative organism, its parts, or its metabolic products, including toxins. Considerations of cost, simplicity and efficiency, make this technique particularly suitable for developing countries. In this paper, we review the scientific basis underpinning this method.

Key words: In vitro selection, Plant disease resistance, Plant tissue culture, Somaclonal variation.

\section{Introducción}

Un hecho ampliamente reportado en los laboratorios de cultivo de tejidos y micropropagación vegetal, es que muchas plantas obtenidas in vitro presentan diferencias fenotípicas, morfológicas o bioquímicas en comparación con el fenotipo de las plantas donadoras de los explantes. Larkin y Scowcroft (1981), distinguieron claramente dos tipos de causas: la variación epigenética transitoria, debida probablemente a las condiciones de estrés gene- radas por las condiciones propias del cultivo de tejidos y células in vitro, y las variaciones genéticas "verdaderas", producto de mutaciones azarosas. En cualquier caso, el fenómeno se conoce como variación somaclonal.

Las variaciones epigenéticas, debido a su naturaleza, son inestables y se revierten con una alta frecuencia en las líneas celulares, sin que haya consecuencias fenotípicas en las plantas regeneradas (Sánchez-Chiang \& Jiménez 2009). Por el contrario, la variación somaclo- 
nal de origen genético sí se transmite y expresa en la descendencia de las plantas regeneradas. Cuando esta capacidad intrínseca de variación de los cultivos crecidos in vitro es potencializada a través de la adición de un agente de selección al medio de cultivo, es posible obtener variantes "somaclonales" con tolerancia a ese agente de selección; esta técnica se denomina "selección in vitro" (Lestari 2006).

Aunque la variabilidad genética es esencial para la creación de plantas con características agronómicas superiores, las mutaciones espontáneas ocurren con una frecuencia extremadamente baja; por esta razón las técnicas de inducción de variación somaclonal constituyen una potente herramienta para lograr un rápido incremento en la variabilidad genética de las especies cultivadas (Okole et al. 2000). En este procedimiento la presión de selección puede ser aplicada a un número de células considerablemente, evitando la selección de plantas individuales en pruebas de campo convencionales. El agente de selección puede ser de origen biótico o abiótico (v.gr. metales pesados, sales, herbicidas, fitotoxinas, virus, etc.), de acuerdo con los fines que se persigan (Lestari 2006).

En general, el tejido más ampliamente usado para la selección es el callo, aunque pueden utilizarse también otros explantes que conducen a una organogénesis directa. El callo tiene la ventaja de ser producido fácilmente y de que puede regenerarse potencialmente en plántulas. Además, la carencia de cutícula facilita la toma de moléculas pequeñas tales como las fitotoxinas (Okole et al. 2000).

La selección in vitro ha sido aplicada a varios tipos de cultivos, en los cuales se han utilizado varios agentes de selección. En tomate ( (Lycopersicon esculentum Mill.), por ejemplo, la selección in vitro ha sido explotada con éxito en la búsqueda de líneas tolerantes a varios tipos de estrés bióticos y abióticos como la presencia de sales, drogas y fitotoxinas (Bhatia et al. 2004).

Aunque las ventajas del método de selección in vitro pueden ser las mismas para todo fin, en el caso de la búsqueda de líneas resistentes a enfermedades sus beneficios son evidentes. Por un lado, los métodos convencionales de mejoramiento que buscan la resistencia a enfermedades son altamente demandantes de tiempo, costosos, y dependen de las fluctuaciones naturales en la abundancia del inóculo; por otro lado, estos métodos están condicionados a los factores que influyen en la dispersión del patógeno, la infección, el desarrollo y expresión de la enfermedad (Borras et al. 2001). En comparación, la selección in vitro requiere menos esfuerzo y una menor implementación logística, además de que, no se ve influenciada por las complicaciones relacionadas con los factores epidemiológicos que usualmente afectan los procedimientos de selección en campo.

\section{Variación somaclonal como fundamento de la selección in vitro}

El cultivo de células, tejidos y órganos vegetales in vitro está generalmente asociado a varios problemas de calidad fisiológica, epigenética y genética, como la recalcitrancia, la hiperhidricidad y la variación somaclonal (Cassells \& Curry 2001). Aunque esta última puede ser indeseable en algunos casos, como cuando se requiere mantener la identidad clonal del material propagado, también tiene implicaciones importantes para los programas y estrategias de fitomejoramiento (Karp 1995, Jain 2001).

Existen varios factores que inciden en la obtención de variación somaclonal (Karp 1995). Como regla general, entre mayor sea el nivel de desorganización del tejido del explante y mayor el tiempo que éste pasa en la fase de cultivo in vitro, mayores serán las probabilidades de generar variación somaclonal. Esta variación se ve influenciada por la constitución genotípica y los niveles de ploidía del explante, por lo que si se considera un mismo grado de ploidía, algunos genomas pueden ser más estables que otros. El tipo y la concentración de reguladores de crecimiento en el medio de cultivo influyen también en la generación de variación somática ya que éstos pueden actuar como mutágenos (especialmente los sintéticos), o influir sobre la división celular, el grado de crecimiento desorganizado y la proliferación selectiva de tipos celulares específicos. Por último, generalmente se observa que, entre más viejo y más especializado es el explante, mayor es la posibilidad de recuperar variación en las plantas regeneradas. Jelenic y colaboradores (2001) plantearon la importancia de las condiciones ambientales durante el cultivo y la presencia o ausencia de agentes selectivos in vitro, como generadores de variación. 
A nivel molecular, la ocurrencia de variación somaclonal está asociada a mutaciones puntuales, rearreglos y recombinaciones cromosómicas, metilación del $\mathrm{ADN}$, alteración en el número de copias de segmentos de $\mathrm{ADN}, \mathrm{y}$ ocurrencia de elementos transponibles (Jain, 2001), estos aspectos se detallan a continuación.

\section{Citogenética de la variación somaclonal}

Se ha demostrado que la variación somaclonal está asociada a cambios cromosómicos de diferente tipo y en diferentes niveles, y que es virtualmente ubicua para todas las especies con protocolos de regeneración en cultivo in vitro (Lee \& Phillips 1988, Jain 2001). En un contexto general, los cambios incluyen aneuploidias y euploidias de las células cultivadas $y$ los regenerantes. A nivel estructural, se han observado deleciones, adiciones, translocaciones, inversiones e incluso fusiones de cromátidas no homólogas. Los cambios más frecuentes en la mayoría de las especies son los de tipo estructural, y dentro de estos, los que involucran pérdida de cromatina (Lee \& Phillips 1988). Cualquiera que sea el tipo de modificación estructural, siempre requiere la ruptura de la cromatina y en algunos casos el intercambio y unión de las moléculas.

Se ha demostrado que estos eventos de rearreglos y deleciones cromosómicos pueden involucrar cromosomas específicos o regiones específicas dentro de los mismos, las cuales habitualmente incluyen segmentos de heterocromatina (Lee \& Phillips 1988). El hecho de que la variación somaclonal esté asociada con las regiones heterocromáticas, puede deberse a que éstas presentan una replicación tardía en la fase $S$ (Turner 2001), que puede propiciar fallas en los mecanismos de regulación de la transición entre las fases $\mathrm{S}$ y $\mathrm{M}$ del ciclo celular (Lee \& Phillips 1988). Sin embargo, aunque varias investigaciones sugieren que genomas con mayor contenido de heterocromatina generan más variantes somaclonales que aquellos con un contenido menor; otras han demostrado una relación inversa entre el contenido de heterocromatina y la variación somaclonal (Karp 1995).

Lee y Phillips (1988) propusieron otros mecanismos citológicos que podrían causar o hacer parte del proceso de variación somá- tica. En primer lugar está el desbalance en la reserva de nucleótidos intracelulares que se presenta durante el ciclo del cultivo in vitro. En segundo lugar, hay diferentes formas de recombinación mitótica que incluyen el entrecruzamiento somático y el intercambio de cromátides hermanas y también no homólogas, los cuales podrían producir varios de los tipos de rearreglos cromosómicos observados en cultivo de tejidos.

\section{Elementos transponibles y variación somaclonal}

El hallazgo de elementos transponibles en cultivo de tejidos de maíz, sugirió una posible relación entre la variación somaclonal y estos elementos móviles (Lee \& Phillips 1988). Los elementos transponibles, en particular los retrotransposones, son ubicuos dentro de los genomas vegetales y pueden representar el $50 \%$ de la secuencia de éstos (Kumar \& Bennetzen 1999), o hasta el $90 \%$ en especies con un muy alto contenido de $\mathrm{ADN}$, pero con un número similar de genes (Heslop-Harrison et al. 1997).

Datos de hibridación in situ sobre cromosomas metafásicos y sobre el núcleo profásico han revelado que secuencias de retrotransposones tales como el Ty1-copia 19 están dispersos a todo lo largo de la eucromatina, algunas veces aleatoriamente y otras no aleatoriamente dependiendo de la especie vegetal y del tipo de elemento móvil estudiado (Heslop-Harrison et al. 1997). Sin embargo, muchos elementos están presentes en muy poca cantidad o ausentes en ciertas regiones (v.gr., centrómeros, regiones heterocromáticas intersticiales y terminales y sitios de ADN ribosomal) (Kumar \& Bennetzen 1999).

Los retrotransposones, al igual que los elementos transponibles, pueden generar mutaciones insertándose dentro o próximos a los genes. Más aún, los retrotransposones inducen mutaciones que son relativamente estables dado que ellos se transponen vía replicación, reteniendo la secuencia en el sitio de inserción. Estas mutaciones pueden ser causa de inactivación génica o alteraciones en los patrones de expresión de los genes, o de la estructura de las proteínas que codifican (Kumar \& Bennetzen 1999). De hecho, se debe esperar que genomas que portan elementos transponibles sean más inestables en cultivo in vitro que aquellos 
que no los poseen, o los tienen en menor cantidad (Karp 1995).

En este sentido, existe evidencia suficiente de que un porcentaje significativo de las mutaciones en las plantas manipuladas in vitro son debidas a la activación inducida de retrotransposones durante el proceso de cultivo de células y tejidos (Kumar \& Bennetzen 1999). Sin embargo, Kubis y colaboradores (2003) clonaron por PCR fragmentos de retroelementos del grupo gipsy y del grupo LINE y de los transposones En/Spm, a partir del genoma de palma de aceite, sin encontrar diferencia en la organización genómica de las diferentes clases de elementos transponibles entre palmas provenientes de semillas (parentales) y aquellas regeneradas mediante cultivo de tejidos que presentaban una morfología anormal y aborto floral.

\section{Papel de las especies reactivas de oxígeno (ROS) en la variación somaclonal}

Las ROS son otra causa de variación somaclonal, ya que su influencia sobre el ciclo celular puede resultar en la generación de mutaciones por el daño oxidativo que ejercen sobre el ADN nuclear y organelar, a través de un potencial redox celular alterado (Cassells \& Curry 2001). Son sustancias que se originan como subproductos de las rutas metabólicas normales de la planta, especialmente en las reacciones fotosintéticas y de respiración. El sistema de transporte de electrones de la fotosíntesis tiene el potencial para producir especies activas como el singlete de oxígeno y el radical superóxido. Esta última molécula puede a su vez generar peróxido de hidrógeno (Arora et al. 2002). Aunque el radical superóxido y el peróxido de hidrógeno son relativamente poco peligrosos, en presencia de iones de hierro o iones de cobre producen el radical hidroxilo, muy reactivo sobre los sustratos orgánicos (Arora et al. 2002). En presencia de estos mismos iones, las ROS también pueden generar moléculas altamente mutagénicas, tales como los radicales peroxil y alcoxil (Cassells \& $\mathrm{Cu}$ rry 2001).

Bajo condiciones fisiológicas normales, los efectos y potenciales daños de estas especies químicas son controlados por sistemas endógenos que involucran enzimas y diferentes sustancias antioxidantes que mantienen la homeostasis de la célula vegetal. Sin embargo, los niveles de ROS se incrementan bajo condiciones de estrés. Las prácticas de corte del explante al inicio del cultivo in vitro y en los subcultivos posteriores pueden por sí mismas generar estrés oxidativo, de la misma forma en que lo hacen el hipoclorito y/o las sales de mercurio que se utilizan en la esterilización de los tejidos (Cassells \& Curry 2001).

El daño oxidativo en el cultivo de tejidos puede expresarse como hipermetilación o hipometilación del ADN, cambios en el complemento cromosómico incluyendo poliploidías y aneuploidías, rompimiento de las hebras cromosómicas, rearreglos cromosómicos y deleciones y substitución de bases nucleotídicas (Cassells \& Curry 2001).

\section{Metilación epigenética del ADN y variación somaclonal}

Varios reportes en los últimos años han mostrado una correlación entre la hipermetilación de residuos de citosina en el $\mathrm{ADN}$, próximo o dentro de los genes o los promotores génicos, y los niveles reducidos de expresión génica (Kubis et al. 2003). La acetilación de histonas y la metilación del ADN trabajan en combinación para regular la transcripción epigenéticamente (Joyce et al. 2003).

Kubisy colaboradores (2003) encontraron que en la palma de aceite la variación somaclonal estuvo asociada a un nivel y patrón diferente de metilación de las secuencias del ADN. Durante el cultivo de tejidos, la digestión con la endonucleasa de restricción McrBC reveló una reducción a lo largo de todo el genoma en la metilación del $\mathrm{ADN}$, la cual se restauró prácticamente a los niveles normales en los árboles regenerados. Los análisis con HPLC mostraron que los niveles de metilación eran levemente más bajos en los árboles regenerados comparados con la planta parental. Los autores concluyen así, que la alteración en la metilación del ADN es una posible causa de una expresión génica anormal (Kubis et al. 2003).

\section{Utilización de fitotoxinas en programas de selección in vitro para resistencia a enfermedades}

Cuando se pretende llevar a cabo un programa de selección in vitro para resistencia a en- 
fermedades en plantas, los explantes deben someterse a la acción de uno o más agentes que hagan presión de selección sobre las células en la etapa de cultivo. Estos agentes pueden incluir las células mismas del patógeno, filtrados de cultivo, o sustancias purificadas que tengan papeles esenciales en el proceso patogénico. Entre estas últimas, las fitotoxinas han sido ampliamente utilizadas, particularmente cuando se trata de enfermedades fungosas ya que muchos hongos producen toxinas que pueden desactivar las funciones celulares del hospedero o matar a las células huésped antes de la infección o durante una etapa necrotrófica. Por esta razón, los ensayos de selección normalmente implican la evaluación previa de la fitotoxicidad (Patiño 2010).

Yoder (1980) definió las fitotoxinas como metabolitos producidos por el patógeno, que son requeridos para que ocurra la enfermedad o que, aunque no estén implicados en el inicio de la enfermedad, son requeridos como componente parcial para su desarrollo. En consecuencia, según existen fitotoxinas requeridas para la patogenicidad y fitotoxinas requeridas para la virulencia. Cuando actúan como factor de patogenicidad (entendida ésta como un criterio cualitativo), la toxina es esencial para que el patógeno cause la enfermedad, en tanto que cuando actúan como factor de virulencia (entendido como un término cuantitativo) la toxina incrementa la extensión de la enfermedad (Mitchell 1984). Según Lucas (1998) las fitotoxinas tienen dos propiedades importantes, tienen actividad a muy bajas concentraciones y son móviles dentro de la planta por lo que pueden actuar a distancia desde el sitio de infección.

Como grupo, estas toxinas no tienen características estructurales comunes. Pertenecen a clases tan diversas como péptidos u otros derivados de aminoácidos, terpenoides, glicósidos, fenoles, derivados de poliacetato $\alpha$-pirona y polisacáridos, o una combinación de estas y otras clases de moléculas (Strobel 1982). Cómo y en qué nivel influyen estas toxinas en el proceso de patogénesis para un patosistema particular es materia de debate permanente dado su alto grado de heterogeneidad estructural y funcional, debido también a que el estado de enfermedad es un proceso sumamente complejo del que no se conocen todos los detalles a nivel bioquímico, fisiológico y molecular.
Sin embargo, el examen de los síntomas de una enfermedad puede hacer presumir que una toxina está implicada en la patogénesis. El amarillamiento, la marchitez, las lesiones de colores brillantes y la necrosis, son causadas generalmente por toxinas. Además, si los síntomas se producen en sitios alejados del sitio de infección (penetración) del patógeno, puede sospecharse muy fuertemente que una fitotoxina está involucrada en el desarrollo de la enfermedad (Strobel 1982).

Cuando se tienen en cuenta las actividades y efectos biológicos, antes que sus cualidades estructurales, se reconocen dos grandes grupos de toxinas: Las toxinas específicas o selectivas de hospedero y las toxinas no específicas o no selectivas de hospedero (Yoder 1980, Lucas 1998). Las primeras fueron descritas por Pringle y Scheffer (1964) como productos metabólicos de un microorganismo patógeno que son tóxicos únicamente para un hospedero determinado y son determinantes del rango de hospederos y/o de la especificidad del patógeno (Walton 1996, Osbourn 2001, Thomma 2003). Por su parte, las toxinas no selectivas de hospedero son producidas tanto por hongos como por bacterias fitopatógenas y su principal cualidad es que afectan un amplio rango de especies vegetales, incluso aquellas que el organismo productor de la toxina normalmente no infecta. Estas toxinas contribuyen a la virulencia o al desarrollo de síntomas en la enfermedad, pero por definición las toxinas no selectivas no son determinantes primarios del rango de hospedero (Walton 1996).

\section{Ensayos de fitotoxicidad}

A pesar de ser semicuantitativa, la prueba crítica de la fitotoxicidad de una sustancia es la inducción de síntomas completos o parciales de la enfermedad, los cuales se presentan después de la aplicación de tal sustancia a los tejidos intactos o lacerados del hospedero, un ejemplo de esto es la aparición de necrosis y clorosis cuando la toxina se inocula en las hojas (Strobel 1982). Otros bioensayos útiles para probar la toxicidad son la inhibición de la germinación de semillas y la inhibición del crecimiento radical (Jayasankar et al. 1999, Walton 1996).

Los ensayos cuantitativos son aquellos en los cuales la lesión causada por la toxina es medida directamente y usualmente son preferidos 
para la evaluación del efecto de la toxicidad. Por ejemplo, la alteración del plasmalema puede medirse por la liberación de electrolitos o la depolarización de la membrana (Strobel 1982). Estas aproximaciones cuantitativas y semicuantitativas son válidas tanto para toxinas selectivas como no selectivas de hospedero (Jayasankar et al. 1999, Walton 1996).

\section{Uso de toxinas para la generación de materiales vegetales con resistencia a enfermedades}

En 1973, Carlson demostró por primera vez que las células y protoplastos vegetales podrían ser seleccionados en cultivo para resistencia a toxinas de patógenos y que podían regenerarse plantas con una respuesta alterada a la infección por el patógeno a partir de estas células cultivadas in vitro (Daub 1986, Jayasankar \& Gray 2003).

La selección in vitro usando fitotoxinas puede ofrecer una alternativa a la selección en campo como se ha demostrado para varias interacciones planta-patógeno y puede permitir la selección de características importantes en la resistencia a enfermedades a través de la selección de somaclones (Dugdale et al. 2000, Borras et al. 2001). Se han desarrollado varios protocolos eficientes de selección para resistencia a varios patógenos de plantas usando filtrados de cultivo y toxinas purificadas en experimentos de selección (Patiño et al. 2007), en los que la sensibilidad de la planta a la toxina y una evidencia de la susceptibilidad de la planta intacta al patógeno, son requisitos para el éxito.

Un método de selección para resistencia es la selección en un solo paso, en la cual se agrega una concentración letal del agente selectivo al medio de cultivo; otro método es la selección paso a paso, en la cual la concentración del agente selectivo se incrementa gradualmente, hasta que se llega a una concentración letal (Borras et al. 2001).

Dando por supuesta la existencia de un protocolo de regeneración de la especie vegetal, la primera etapa en el procedimiento es el aislamiento y purificación de las toxinas involucradas. Las fitotoxinas pueden aislarse de los patógenos cuando éstos crecen bajo condiciones de cultivo y una vez que el parásito se remueve del medio de cultivo por filtración o centrifugación, las substancias pueden separarse de acuerdo con su tamaño molecular, ya sea por precipitación con solvente o cromatografía sobre filtros moleculares. Para las toxinas de menor tamaño, puede usarse la extracción directa con solventes y la subsiguiente purificación con HPLC $\mathrm{u}$ otras técnicas cromatográficas (Strobel 1982).

Una vez hecho esto, el paso siguiente es comprobar la actividad biológica de la toxina en el tejido de la planta para la cual se busca resistencia. Borras y colaboradores (2001) encontraron una correlación directa entre la concentración de filtrado de cultivo de Fusarium subglutinans y el área necrosada de segmentos foliares de variedades susceptibles de piña, inoculados con los filtrados. Demostraron además que el filtrado necrosaba el tejido foliar de variedades resistentes, pero en una proporción menor que el de las variedades susceptibles. Según los autores, este último punto demostraría que el ácido fusárico, principal componente del filtrado, tiene un comportamiento no específico sobre variedades susceptibles y resistentes. Una vez comprobada la actividad fitotóxica, el filtrado que contiene la toxina o la toxina purificada, es usado como agente de selección e incluido en el medio de siembra para el cultivo in vitro del explante de la planta a seleccionar. Bajo estas condiciones puede esperarse que sólo las células que han adquirido resistencia a la toxina crezcan y se dividan y sin éstas las que se seleccionan para los protocolos de regeneración. El mecanismo que subyace a la aparición de este nuevo estado de "resistencia" en el material previamente susceptible, es la variación somaclonal.

Existen varios ejemplos de la aplicación de toxinas y otros factores de estrés como agentes de selección en los cuales se han obtenido evidencias de resistencia originada por variación somaclonal. En la berenjena, una especie de solanácea, se han obtenido variantes somaclonales con resistencia a enfermedades y con tolerancia a la salinidad (Collonnier et al. 2001). Nyange et al. (1995) generaron protoplastos y células con resistencia a Colletotrichum kahawae en plantas de café; Jayasankar y colaboradores (1999) encontraron que cultivos embriogénicos de mango seleccionados contra el filtrado de cultivo o fitotoxinas de C. gloeosporioides, presentaron una resistencia aumentada contra el patógeno y expresaron nuevas proteínas relacionadas con la patogénesis in vitro. Ejemplos adicionales se dan en 
Jayasankar y Gray (2003), Jayasankar (2005) y Lestari y colaboradores (2006).

\section{Perspectivas}

La selección in vitro ha sido ampliamente utilizada a nivel mundial para la producción de germoplasma vegetal resistente o tolerante a enfermedades (Jayasankar \& Gray 2003) y limitantes abióticos (Jayasankar 2005, Lestari 2006). Sin embargo, ha sido subutilizada en Colombia y Latinoamérica, según puede verse al hacer una búsqueda de literatura sobre el tema en la base de datos latinoamericana Scielo (www.scielo.org). Los reportes encontrados evidencian el uso de la técnica en Brasil y Colombia, con esfuerzos dirigidos a la obtención de material vegetal con tolerancia a la salinidad (Ulisses et al. 2000, Ulisses et al. 2002, Barroso et al. 2003), a altos niveles de aluminio (Dantas et al. 2001) o a fitopatógenos (Patiño et al. 2007, Gomes-Oliveira \& Matsumura 2001).

En la región, y particularmente en Colombia, existen laboratorios y un recurso humano altamente calificado en las diferentes técnicas de cultivo de tejidos y resulta sorprendente que esta técnica no haya sido adoptada con mayor frecuencia pese a sus ventajas. Las consideraciones sobre los aspectos financieros, logísticos $\mathrm{y}$ ambientales asociados, permiten considerar a la selección in vitro como una herramienta oportuna y particularmente apta para las condiciones socioculturales y económicas de los países en vía de desarrollo; en tal sentido, los grupos de investigación en biotecnología agrícola del país, adscritos a entidades de carácter público y privado, deberían evaluar sus potencialidades y considerar su implementación.

Como punto de partida en este sentido, la técnica de selección in vitro tiene algunas ventajas que hacen que su uso sea recomendable: a) no implica técnicas de manipulación genética molecular; b) permite la manipulación simultánea de un número prácticamente ilimitado de células en un solo ciclo de selección, lo que aumenta la probabilidad de obtener algún mutante con una respuesta fenotípica adecuada a los fines del mejoramiento; c) existen protocolos de regeneración in vitro efectivos para muchas especies de importancia económica, lo que garantiza una aplicabilidad amplia de la técnica; d) hay disponibilidad de muchas técnicas moleculares para una discriminación rápida y eficaz de variantes genéticos vs. variantes epigenéticos; e) no requiere de insumos o infraestructura especializada y $f$ ) es una técnica bien sustentada científicamente.

En cuanto a los fines, la técnica se adapta fácilmente a las siguientes necesidades: a) generación de germoplasma resistente/tolerante a factores de estrés abiótico (v.gr. estrés hídrico, salinidad, metales pesados), condición que generalmente tiene una base genética compleja; b) selección directa de mutantes con tolerancia y/o resistencia a factores bióticos con base genética monogénica; c) generación de ornamentales con características novedosas (v.gr. tamaño, color, textura) y d) estudio y análisis de los mecanismos de interacción molecular entre las células de las plantas y los fitopatógenos, así como las respuestas de las células vegetales a los estrés abióticos.

\section{Discusión y Conclusiones}

La variación somaclonal es el resultado de eventos aleatorios, genéticos o epigenéticos, que ocurren durante el proceso de cultivo de tejidos y que modifican el fenotipo de las plantas y/o tejidos regenerados. Aunque tal variación en el fenotipo puede tener consecuencias indeseadas en algunos casos, en otros constituye un método práctico para generar variabilidad en el reservorio genético de la mayoría de las especies vegetales.

Los mecanismos responsables de la variación somaclonal varían desde la pérdida de segmentos cromosómicos hasta cambios nucleotídicos puntuales y cambios en los patrones de metilación del ADN. Sin embargo, en la mayoría de los casos las causas son multifactoriales. Aunque el fenómeno es inherente al procedimiento de cultivo de tejidos, la tasa de aparición de variantes somaclonales puede incrementarse a través del uso de sustancias que ejercen una presión de selección sobre el explante y de esta forma, obtener células con adaptación al agente de selección. Si éste es una fitotoxina, pueden obtenerse, en teoría, plantas con algún grado de resistencia o tolerancia al patógeno productor de la toxina. Esta práctica se denomina selección in vitro.

Debido a su bajo costo, sencillez y eficacia, éste es un proceso biotecnológico de amplio potencial para los países del trópico, en especial para su aplicación en germoplasmas con reservas genéticas estrechas. 


\section{Literatura citada}

Arora, A., R.K. Sairam \& G.C. Srivastava. 2002. Oxidative stress and antioxidative system in plants. Current Science 82: 1227-1238

Barroso, P.A.V., G.E.D.D. Moura, L.K.F. Brito, C.P. Martins, C.E.C. Macedo, D.B. Lopes \& M.A.I. Alloufa. 2003. Efeito do cultivo in vitro na presença de $\mathrm{NaCl}$ em plantas de abacaxizeiro na fase de aclimatação. Revista Brasileira de Engenharia Agrícola e Ambiental 7: 473-477

Bhatia, P., N. Ashwath, T. Senaratna \& D. Midmore. 2004. Tissue culture studies of tomato (Lycopersicon esculentum). Plant Cell, Tissue and Organ Culture 78: 1-21

Borras, O., A.R. Santos, A.P. Matos, R.S. Cabral \& M. Arzola 2001. A First attempt to use a Fusarium subglutinans culture filtrate for the selection of pineapple cultivars resistant to fusariose disease. Plant Breeding, 120: 435-438

Cassells, A.C. \& Curry, R.F. 2001. Oxidative stress and physiological, epigenetic and genetic variability in plant tissue culture: implications for micropropagators and genetic engineers. Plant Cell, Tissue and Organ Culture 64: 145157

Collonnier, C.,I. Fock, V. Kashyap,G.L. Rotino, M.C. Daunay, Y. Lian, I.K. Mariska, M.V. Rajam, A. Servaes, G. Ducreux \& D. Sihachakr. 2001. Applications of biotechnology in eggplant. Plant Cell, Tissue and Organ Culture65: 91107

Dantas, A.C.M., G.R.L. Fortes, J.B. da Silva, A.N. Nezi \& A.C. Rodrigues. 2001. Tolerância ao alumínio em porta-enxertos somaclonais de macieira cultivados em solução nutritiva. Pesq. agropec. bras. 36: 615-623

Daub, M.E. 1986. Tissue culture and the selection of resistance to pathogens. Annual Review of Phytopathology 24: 159-186

Dugdale, L.J.,A.M. Mortimer,S. Isaac \& H.A. Collin. 2000. Disease response of carrot and carrot somaclones to Alternaria dauci. Plant Pathology 49: 57-67

Gomes-Oliveira, I.V. \& A.T.S. Matsumura. 2001. Técnica de obtenção de filtrado de cultura de Alternaria solani. Fitopatol. bras. 26: 102

Heslop-Harrison, J.S., A. Brandes,S. Taketa, T. Schmidt, A.V. Vershinin,E.G. Alkhimova, A. Kamm, R.L. Doudrick,T. Schwarzacher, A. Katsiotis,S. Kubis, A. Kumar, S.R. Pearce, A.J. Flavell, \& G.E. Harrison. 1997. The chromosomal distributions of Ty1-copia group retrotransposable elements in higher plants and their implications for genome evolution. Genetica 100: 197-204
Jain, S.M. 2001. Tissue culture-derived variation in crop improvement. Euphytica 118: 153-166

Jayasankar, S. 2005. Variation in tissue culture. In: Trigiano, R. \& Gray, D. J. (Editors). Plant development and biotechnology. CRC Press, LLC, USA. $358 \mathrm{pp}$

Jayasankar, S. \& D. Gray. 2003. In vitro selection for disease resistance in plants-an alternative to genetic engineering. AgBiotechNet Vol. 5 May ABN 111.5 pp.

Jayasankar, S., R. Litz., D.J. Cray \& P. Moon. 1999. Responses of embriogenic mango cultures and seedlings to bioassays to a partially purified phytotoxin produced by a mango leaf isolate of Colletotrichum gloeosporiodes Penz. In Vitro Cell. Dev. Biol. Plant 35: 475-479

Jelenic, S., J. Berljak, , D. Papes, \& S. Jelaska. 2001. Mixoploidy and chimeric structures in somaclones of potato (Solanum tuberosum L.) cv. Bintje. Food Technol. Biotechnol. 39: 13-17

Joyce, S.M., Cassells, A. C. \& Jain, S. M. 2003. Stress and aberrant phenotypes in in vitro culture. Plant Cell, Tissue and Organ Culture, 74: 103-121

Karp, A. 1995. Somaclonal variation as a tool for crop improvement. Euphytica 85: 295-302

Kubis, S.E., A.M.M.F. Castilho,A.V. Vershinin \& P.S. Heslop-Harrison. 2003. Retroelements, transposons and methylation status in the genome of oil palm (Elaeis guineensis) and the relationship to somaclonal variation. Plant Molecular Biology 52: 69-79

Kumar,A.\&J.L.Bennetzen.Plant retrotransposons. Annual Review of Genetics 33: 479-532

Larkin, P.J, \& W.R. Scowcroft 1981. Somaclonal variation-a novel source of variability from cell culture for plant improvement. Theor Appl Genet, 60: 197-214

Lee, M. \& R. Phillips.1988. The chromosomal basis of somaclonal variation. Annual Review of Plant Physiology and Molecular Biology 39: 413-437

Lestari, E.G. 2006. In vitro selection and somaclonal variation for biotic and abiotic stress tolerance. Biodiversitas 7(3): 297-301

Lucas, J.A. 1998. Plant pathology and plant pathogens. Third edition. Blackwell Science Ltd. 274 pp.

Mitchell, R.E. 1984. The relevance of non-hostspecific toxins in the expression of virulence by pathogens. Annual Review of Phytopathology 22: $215-245$

Nyange, N.E., B. Williamson, R.J. McNicol, J.D. Lyon \& C.A. Hackett. 1995. In vitro selection of Coffea arabica callus for resistance to partially purified phytotoxic culture filtrates from Colletotrichum kahawae. Annals of Applied 
Biology, 127: 425-439

Okole, B., C. Memela, S. Rademan \& K.J. Kunert. 2000. Non-conventional breeding approaches for banana and plantain improvement against fungal diseases at Aeci. Acta Hort. 540: 207214

Osbourn, A.E. 2001. Tox-boxes, fungal secondary metabolites, and plant disease. Proceedings of the National Academy of Sciences USA 98: 14187-14188

Patiño Torres, C. 2010. Producción in vitro de pectinasas por Colletotrichum acutatum. Acta Agronómica 59: 80-90

Patiño Torres, C., R. Hoyos Sánchez \& L. Afanador Kafuri. 2007. Selección y regeneración in vitro de somaclones de tomate de árbol (Solanum betacea cav. Sendt) utilizando filtrados de cultivo de Colletotrichum acutatum con actividad pectinasa. Rev. Fac. Nal. Agr. Medellín 60: 3923-3937

Pringle, R.B. \& R.P. Scheffer. 1964. Host-Specific Plant Toxins. Annual Review of Phytopathology 2: $133-156$

Sánchez-Chiang, N. \& V. Jiménez. 2009. Técnicas moleculares para la detección de variantes somaclonales. Agronomía Mesoamericana 20(1): 135-151.

Strobel, G.A. Phytotoxins. 1982. Annual Review of Biochemistry 51: 309-333

Thomma, B.P.H.J. 2003. Alternaria spp.: from general saprophyte to specific parasite. Molecular Plant Pathology 4: 225-236

Turner, B.M. 2001. Chromatin and gene regulation. Blackwell Science Ltd. 284 pp.

Ulisses, C., T.R. Camara, L. Willadino, I. Meunier, P.S. Gomes da Rocha \& C. Albuquerque. 2000. Seleção in vitro de gemas de bananeira 'nanicão' tolerantes à salinidade. Scientia Agricola 57: 667-670

Ulisses, C., T.R. Camara, L. Willadino, C.C. de Albuquerque, L.S.S. Martins \& N.S.A. de Freitas. 2002. Caracterização isoenzimática de clones de bananeira nanicão submetidos à salinidade. Revista Brasileira de Engenharia Agrícola e Ambiental 6: 358-361

Walton, J.D. 1996. Host-selective toxins: agents of compatibility. The Plant Cell 8: 1723-1733

Yoder, O.C. 1980. Toxins in pathogenesis. Annual Review of Phytopathology 18: 103-129

Recibido: 4 de junio de 2010

Aceptado: 12 de julio de 2010 